\title{
In vitro and in vivo evaluation of an intraocular implant for glaucoma treatment
}

\author{
Mădălina V. Natu ${ }^{\mathrm{a}}$, Manuel N. Gaspar ${ }^{\mathrm{b}}$, Carlos A. Fontes Ribeiro ${ }^{\mathrm{b}}$, \\ António M. Cabritac ${ }^{c}$,Hermínio C. de Sousa ${ }^{a}$, M. H. Gila, ${ }^{a, 1, *}$ \\ ${ }^{a}$ Department of Chemical Engineering, University of Coimbra, Pólo II, 3030-790, \\ Coimbra, Portugal \\ ${ }^{b}$ Institute of Pharmacology and Experimental Therapeutics, University of Coimbra, Pólo \\ III, 3000-354, Coimbra, Portugal \\ ${ }^{c}$ Institute of Experimental Pathology, University of Coimbra, Pólo I, 3004-504, Coimbra, \\ Portugal
}

\begin{abstract}
Implantable disks for glaucoma treatment were prepared by blending poly $(\varepsilon-$ caprolactone), PCL, poly(ethylene oxide)-b-poly(propylene oxide)-b-poly(ethylene oxide) and dorzolamide. Their in vivo performance was assessed by their capacity to decrease intraocular pressure (IOP) in normotensive and hypertensive eyes. Drug mapping showed that release was complete from blend disks and the low molecular weight (MW) PCL after 1 month in vivo. The high MW PCL showed non-cumulative release rates above the therapeutic level during 3 months in vitro. In vivo, the fibrous capsule formation around the implant controls the drug release, working as a barrier membrane. Histologic analysis showed normal foreign body reaction response to the implants. In normotensive eyes, a $20 \%$ decrease in IOP obtained with the disks during 1 month was similar to Trusopt ${ }^{\circledR}$ eyedrops treatment. In hypertensive eyes, the most sustained decrease was shown by the high MW PCL (40\% after 1 month, $30 \%$ after 2 months). It was shown that the implants can lower IOP in sustained manner in a rabbit glaucoma model.
\end{abstract}

Keywords: $\operatorname{poly}(\varepsilon$-caprolactone), subconjunctival implant, controlled drug release, in vivo, intraocular pressure, glaucoma

\footnotetext{
*Corresponding author

Email address: hgil@eq.uc.pt (M. H. Gil)

$1_{\text {tel: }+351239798700, \text { fax:+351239798703 }}$
} 


\section{Introduction}

Glaucoma is a chronic condition that requires long-term treatment in order to stop progressive and irreversible blindness ([1]). Treatment of glaucoma focuses on preserving vision by slowing down damage to the optic nerve. Therapy aims at preventing further damage by lowering IOP (or ocular hypertension) and it usually consists of pharmaceutical treatment and laser or surgical procedures ([2]). It was shown that reducing IOP is effective in preventing disease progression in ocular hypertension, primary open angle glaucoma, and even in normal tension glaucoma ([3]).

In most glaucoma patients, medical therapy consists of topical eyedrops and oral tablets. However, administration and compliance are often problematic. Eyedrops produce low ocular bioavailability ([4]), unnecessary systemic exposure ([5]) and have low patient compliance due to uncomfortable sensations ([6]), as well as difficulty of instillation or forgetfulness ([7]). Two main strategies have already been used clinically to diminish such effects, namely gel forming (viscous) solutions ([8]) and controlled drug delivery systems (CDDS).

CDDS in the form of intraocular implants can deliver therapeutically effective amounts of drugs to targeted ocular tissues over sustained period of time without significant ocular/systemic side effects ([9]). Thus, CDDS can extremely suitable for chronic diseases, which require a constant level of medication to be maintained in the body over a long period of time. The major motivation for development and use of these devices is that they eliminate the need to take multiple doses of a drug during the day or week, thereby improving patient compliance and therapy outcomes ([4]).

In a previous work, implants based on $\operatorname{poly}(\varepsilon$-caprolactone), PCL were prepared by solvent-casting, followed by dip-coating ([10]). Unfortunately, this preparation method is not reproducible and low drug loadings were achieved. High drug loads are needed for long term treatment of chronic diseases such as glaucoma. Moreover, the volume of such devices should be as small as possible in order to be easily introduced at the implantation site. Melt compression is a reproducible, easily scalable method of producing implants of different shapes and sizes $([11,12])$. In addition, compact implants can be obtained with small polymer-to-drug ratio, which enables high drug loads in a relatively small implant volume. 
The objective of the present work was to prepare a drug loaded biodegradable implant designed to provide a localized, long-term (6 months to 2 years) sustained release of the drug, that can be used in the treatment of glaucoma. A subconjunctival placement of the implant is simple to perform because of easy access to the implantation area and low vascularization. PCL and Lutrol F 127, Lu were selected because they are both biocompatible, biodegradable and they can be easily processed by conventional polymer processing techniques ([13]). Moreover, they are commercially available, inexpensive and well characterised polymers. PCL is a slowly degradable polymer, while Lu can be used as a release modulator $([14,15])$. Two molecular weights of PCL were used because it was shown that molecular weight determines the time lag before erosion and the rate of bioerosion in vivo ([16]). The implantable drug loaded disks were prepared by melt compression and their performance in vivo was evaluated by assessing the capacity to lower IOP in normotensive and hypertensive rabbit eyes.

\section{Materials and methods}

\subsection{Preparation of polymer disks}

Poly( $\varepsilon$-caprolactone) (PCL40, average $M_{w} 65000 \mathrm{~g} / \mathrm{mol}$ and PCL10, average $M_{w} 15000 \mathrm{~g} / \mathrm{mol}$, Sigma-Aldrich) and Lutrol F 127 (Lu, poly(ethylene oxide)-b-poly(propylene oxide)-b-poly(ethylene oxide), 9000-14000 g/mol, 70 $\%$ by weight of polyoxyethylene, BASF) films and dorzolamide hydrochloride (Chemos GmbH) loaded films (Lu/PCL: 13/87, 6/94, 0/100 \% w/w) were prepared by solvent casting from acetone (UV grade, Sigma-Aldrich) at 40 ${ }^{\circ} \mathrm{C}$, using a $15 \% \mathrm{w} / \mathrm{v}$ total polymer concentration and $33.3 \% \mathrm{w} / \mathrm{w}$ theoretical drug loading. Polymer sheets were fabricated by compression moulding of the polymer films in a stainless steel mould by applying a pressure of 201.5 $\mathrm{kg} / \mathrm{m}^{2}$ for 20 minutes at $100^{\circ} \mathrm{C}$. The mould was subsequently cooled under a jet of cold water $\left(20^{\circ} \mathrm{C}\right)$ during 2 minutes. Discs of $4 \mathrm{~mm}$ diameter $(1 \mathrm{~mm}$ thickness, 4-5 mg drug mass, $13-16 \mathrm{mg}$ total mass) were punched from the polymer sheets. They were used as such in characterization tests. Prior to in vivo implantation, the discs were sterilized using UV radiation during 20 minutes (at $254 \mathrm{~nm}$ ) in a UV chamber (Camag UV cabinet).

\subsection{Disk characterization}

Differential scanning calorimetry (DSC) was carried out using a DSC Q100 equipment (TA Instruments) under nitrogen atmosphere (100 mL/min). 
Samples with masses of approximately $5 \mathrm{mg}$ were heated until $100^{\circ} \mathrm{C}$, at a heating rate of $10^{\circ} \mathrm{C} / \mathrm{min}$. The relative crystallinity of the disks was calculated as previously described considering the melting enthalpy of $100 \%$ crystalline PCL and $100 \%$ crystalline Lu [15]. Thermogravimetric analysis (TGA) was carried out using a SDT Q 600 equipment (TA Instruments). Samples with masses of approximately $10 \mathrm{mg}$ were heated until $600^{\circ} \mathrm{C}$, at a heating rate of $10^{\circ} \mathrm{C} / \mathrm{min}$. The degradation temperature $\left(T_{d}\right)$ was determined at the onset point of the TGA plot.

Water contact angle was evaluated by static contact angle measurements using an OCA 20 Video-Based Contact Angle Meter (Dataphysics) and employing the sessile drop method.

Drug loading of the disks was assessed by elemental analysis (quantification of sulphur, present only in the drug molecule).

\subsection{Morphology and drug distribution}

The morphology of the disks (before and after implantation) was examined using scanning electron microscopy, SEM (JSM 5310, Jeol). The drug mapping (elemental sulphur) of the disks surface and cross-section (showing the center of the disk) was done using electron probe microanalysis, EPMA (Camebax SX50, Cameca) at $15 \mathrm{kV}$ accelerated voltage and $40 \mathrm{nA}$ probe current.

\subsection{In vitro and in vivo degradation}

The extent of hydrolytic degradation of the disks (as prepared, in vitro degraded and in vivo degraded) was evaluated by determining the change of MW in time. Polymer disks were placed in $4 \mathrm{~mL}$ PBS with $0.001 \%$ sodium azide, at $37^{\circ} \mathrm{C}$. The changes in the $\mathrm{MW}$ were measured by size exclusion chromatography (SEC), using chloroform as mobile phase $(1 \mathrm{ml} / \mathrm{min}$, $30{ }^{\circ} \mathrm{C}$ ) and a PLgel MIXED-C column (300 $\mathrm{mm} \times 7.5 \mathrm{~mm}, 5 \mu \mathrm{m}$, Varian). PL-EMD 960 (Polymer Laboratories) evaporative light scattering detector was used to acquire the data. Universal calibration was performed using polystyrene (PS) standards and Mark-Houwink parameters $k_{P C L}=1.09$ $\times 10^{-3} \mathrm{dl} / \mathrm{g}, \alpha_{P C L}=0.60, k_{P S}=1.25 \times 10^{-4} \mathrm{dl} / \mathrm{g}, \alpha_{P S}=0.71$. Peak integration was performed using Clarity chromatography software (DataApex).

\subsection{In vitro drug release and release modelling}

Dorzolamide hydrochloride release was studied in $10 \mathrm{ml}$ phosphate saline buffer medium (PBS tablets, pH 7.4, $10 \mathrm{mM}$ phosphate, $137 \mathrm{mM}$ sodium, 
$2.7 \mathrm{mM}$ potassium, Sigma-Aldrich) at $37^{\circ} \mathrm{C}$. At scheduled time intervals, samples were taken and the entire medium volume was replaced with fresh medium to maintain sink conditions. The mass of dorzolamide hydrochloride released at time $t$ was determined by UV spectroscopy at $254 \mathrm{~nm}$ (Jasco V-650 Spectrophotometer). The percentage of in vitro released drug was calculated using Eq.1.

$$
\text { Releaseddruginvitro }(\%)=\frac{M_{d t}}{M_{d 0}} \times 100
$$

In Eq. $1, M_{d t}$ is the drug mass released at time $t$ and $M_{d 0}$ is the initial drug mass.

In order to study the drug release mechanism, the power law equation (Eq.2) which is based on diffusional model of drug transport, was used, where $M_{t} / M_{\text {total }}$ is the fractional release of the drug, $k$ is the kinetic constant and $n$ is the release exponent, indicating the mechanism of drug release [15].

$$
\frac{M_{t}}{M_{\text {total }}}=k t^{n}
$$

An alternative model (Eq.3) based on polymer degradation control of drug release was used to fit the release data. In this model, two pools of drug are considered: a pool of mobile drug which readily diffuses out of the matrix upon immersion in an aqueous medium and a pool of immobilized drug which can diffuse only after matrix degradation [15]. This model can be applied to slow-degrading polymers such as PCL due to the fact that polymer degradation is much slower than drug diffusion and as such it is the rate limiting step for drug transport.

$$
M(\tau)=A_{0}+|\Omega| S_{0}(1-\exp (-\tau)), \bar{\alpha}_{l m n}^{-1} \rightarrow 0
$$

In Eq. $3, A_{0}$ is the load of the mobile drug, $S_{0}$ is the load of immobilized drug, $\tau$ is the dimensionless time and is defined by $\tau=\mu t$ ( $\mu$ is the degradation rate constant) and $\Omega$ is the geometrical factor. The model parameters were determined by non-linear regression and the goodness of the fit was assessed.

\subsection{Disk implantation, glaucoma model, intraocular pressure measurement} and in vivo drug release

New Zealand white rabbits were used in animal experiments in agreement with European Union Council Directive 86/609/EEC regarding the 
protection of animals used for experimental and other scientific purposes as described before $([10])$. The disk implantation procedure and the IOP measurement by tonometry were already described ([10]). In order to produce high IOP, we used a low temperature ophthalmic cautery (Bovie, Aaron Medical) to produce 30 to 50 burns that were directed at the limbal plexus and at the episcleral veins $([17,18])$.

The animals were divided in three groups: group $1(n=26)$ received drug loaded polymer disks (the right eye contained the drug loaded disk-PCL40, PCL10, 6\%Lu,PCL40 and 13\%Lu,PCL40, while the left had the control diskpolymers without drug), group $2(\mathrm{n}=3)$ was submitted to Trusopt ${ }^{\circledR}$ eyedrops (dorzolamide hydrochloride $2 \%$, Chibret) treatment (1 drop twice a day in the right eye, while the left eye received a drop of balanced salt solution, BSS sterile solution, Alcon), while group $3(n=3)$ was the glaucoma model reference.

For in vivo release tests, previously weighed polymer disks were implanted as described before for predetermined periods of time and subsequently removed, cleaned of ocular tissues, rinsed with distilled water and vacuum-dried to constant weight. The in vivo released mass of drug was determined gravimetrically using Eq. 4. In Eq. $4, M_{i}$ is the initial disk mass, $M_{t}$ is the disk mass after implantation time $t, M_{c}$ is the mass loss of the control disk and $M_{d 0}$ is the initial drug mass.

$$
\text { Releaseddruginvivo }(\%)=\frac{M_{i}-M_{t}-M_{c}}{M_{d 0}} \times 100
$$

In vivo drug released percentages were also determined by elemental analysis (the residual drug was determined after in vivo implantation).

\subsection{Histologic evaluation}

The local implant site and important organs were excised for histological evaluation. The collected organs included kidneys, spleen, liver, lung (only after 2 months implantation). The organs and tissue samples were fixed in $10 \%$ neutral buffered formaldehyde. The samples were then embedded in paraffin and dehydrated by isopropanol processing. Thin layers were cut from the samples with a microtome and stained with hematoxylin and eosin for optical microscopy. 


\begin{tabular}{lccc}
\hline Sample & $T_{d}\left({ }^{\circ} \mathrm{C}\right)$ & $T_{m}\left({ }^{\circ} \mathrm{C}\right)$ & Contact angle $(\mathrm{deg})$ \\
\hline PCL40+drug & $279.38,420.20$ & $61.53(0.03)$ & $80.23(2.63)$ \\
PCL40 & 375.51 & $61.26(0.31)$ & $73.88(3.31)$ \\
PCL10+drug & $275.00,420.33$ & $60.67(0.19)$ & $78.26(1.24)$ \\
PCL10 & $269.62,421.88$ & $61.23(0.61)$ & $70.24(1.86)$ \\
6\%Lu,PCL40+drug & - & $61.45(0.42)$ & $46.87(2.78)$ \\
6\%Lu,PCL40 & - & $62.07(0.17)$ & $32.52(2.12)$ \\
13\%Lu,PCL40+drug & - & $58.22(0.26)$ & $39.88(0.80)$ \\
13\%Lu,PCL40 & - & $58.86(0.45)$ & $40.20(2.53)$ \\
Lu & 358.80 & $55.57(0.65)$ & $59.33(0.35)$ \\
\hline
\end{tabular}

Table 1: Water contact angle, melting and degradation temperatures of the disks

\subsection{Statistics}

All values are presented as mean and standard error of the mean (SEM). Experiments were performed in triplicates. Statistical analysis (Student's T-test, independent, two-tailed) was done using OpenOffice.org Calc 3.1.

\section{Results and discussion}

\subsection{Disk characterization}

In Table 1, melting $\left(T_{m}\right)$ and degradation temperatures $\left(T_{d}\right)$ are presented for drug loaded and control disks because their knowledge is required when dealing with polymer processing methods for the manufacture of drug-eluting implants. Blend disks are more hydrophilic than PCL disks due to the incorporation of hydrophilic $\mathrm{Lu}([14,15])$ as shown by the lower contact angle values. The low $T_{m}$ enables processing at temperatures much lower than the degradation temperature of dorzolamide $\left(T_{d}=251.26^{\circ} \mathrm{C}\right)$. The PCL samples show a two step degradation process, the first step corresponding to drug degradation, while the second corresponds to polymer degradation.

All disks presented an average content of sulphur of $33.6 \%$, which corresponds to approximately $5 \mathrm{mg}$ of loaded drug in each disk.

\subsection{General considerations about implantation surgical procedure and animal wellbeing}

The surgical procedure to insert the disks is relatively easy to perform because of easy access to the implantation area and low vascularization. 
Moreover, the wound does not need to be sutured because a pocket is created that keeps the disk in place. The fixation of the disk is further enhanced by fast wound healing as the disk is completely encapsulated by the conjunctiva. Ocular adverse events included conjunctivitis (6 eyes in 64 eyes), that resolved clinically in less than 1 week (with antibiotic eyedrops). No other events were observed. It should be mentioned that such ocular adverse events (conjunctival hyperemia, stinging, burning, foreign body sensation, tearing, vision blurring) are quite frequent in topical treatment with eyedrops [6].

\subsection{In vitro and in vivo drug release}

Each disk was loaded with approximately $5 \mathrm{mg}$ of drug in order to achieve a release rate of $18 \mu \mathrm{g}$ /day (similar with the one obtained with Trusopt ${ }^{\circledR}$ $2 \%$ instillation three times a day [19]) for at least 4.5 months (we considered $50 \%$ drug losses during the transport from conjunctiva to cilliary body).

Fig. 1(a) presents the release from blends: release is almost complete after 10 days for $13 \% \mathrm{Lu}, \mathrm{PCL} 40$ and after 20 days for $6 \% \mathrm{Lu}, \mathrm{PCL} 40$. The release kinetics shown in Fig. 1(b) presents similar released drug percentages regardless of the PCL molecular weight.

A comparison between released drug percentages in vitro and in vivo is shown in Table 2. It can be noted that there are significant differences between released percentages in vitro and in vivo for PCL40 and PCL10 samples $(\mathrm{p}=0.07$ and $\mathrm{p}=0.01$, respectively), while the released drug percentages of $6 \% \mathrm{Lu}, \mathrm{PCL} 40$ and $13 \% \mathrm{Lu}, \mathrm{PCL} 40$ are similar in vitro and in vivo $(\mathrm{p}=0.15$ for $6 \% \mathrm{Lu}, \mathrm{PCL} 40)$. In vivo drug released percentages (calculated by mass balance) for PCL40 implant were confirmed by elemental analysis (the residual drug was determined after in vivo implantation): after 8 days, 22.69 (5.82) \% released drug, after 14 days, 24.09 (2.93) \% released drug and after 22 days 35.74 (11.54) \% released drug.

In vivo release kinetics (Fig. 1(c)) seems to approach a zero-order kinetics, while the in vitro kinetics curves (Fig. 1(b)) appear to have a $t^{0.5}$ profile. This may be due to different release controlling phenomena: in vitro, diffusion controls drug release (from here the classic, Fickian $t^{0.5}$ profile), while in vivo, the fibrous capsule formation around the implant (see section 3.7) controls the drug release, functioning as a barrier membrane that slows down release. Thus, there should be significant differences between drug released in vitro and in vivo (see Table 2) for PCL40 and PCL10 samples. For blend samples, due to polymer erosion that takes place mostly in the first day of release [15], the fibrous capsule/barrier control is absent (only after 1 week, the 


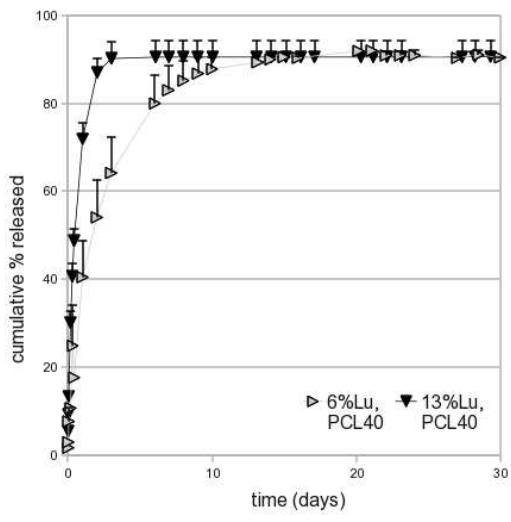

(a)

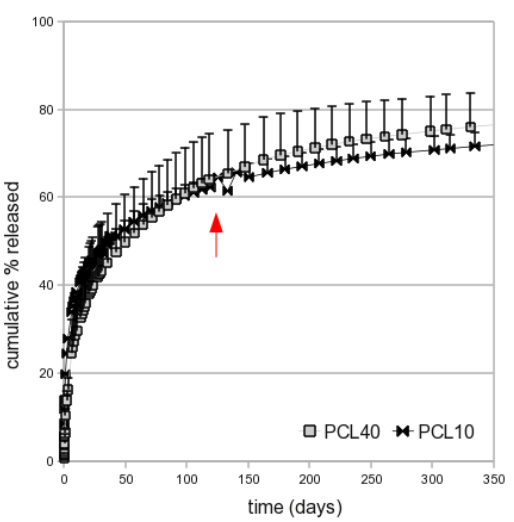

(b)

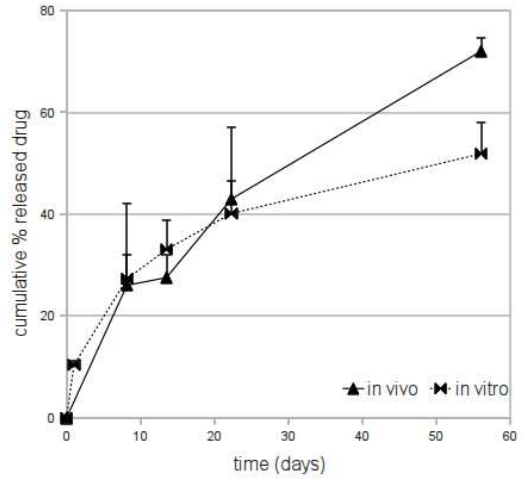

(c)

Figure 1: a), b) In vitro drug release (the red arrow indicates the point on the kinetics curve when the released dose is smaller than the effective dose), c) Comparison between in vivo and in vitro drug release for sample PCL40 


\begin{tabular}{|c|c|c|c|c|c|c|}
\hline \multirow[t]{3}{*}{ Sample } & \multirow{2}{*}{\multicolumn{2}{|c|}{$\frac{\text { In vitro }}{\text { Rel. drug }(\%)}$}} & \multicolumn{4}{|c|}{ In vivo } \\
\hline & & & \multicolumn{2}{|c|}{ Rel. drug mass (mg) } & \multicolumn{2}{|c|}{ Rel. drug (\%) } \\
\hline & $\begin{array}{c}1 \\
\text { month }\end{array}$ & $\begin{array}{c}2 \\
\text { months }\end{array}$ & $\begin{array}{c}1 \\
\text { month }\end{array}$ & $\begin{array}{c}2 \\
\text { months }\end{array}$ & $\begin{array}{c}1 \\
\text { month }\end{array}$ & $\begin{array}{c}2 \\
\text { months }\end{array}$ \\
\hline PCL40 & $\begin{array}{l}40.14 \\
(6.48)\end{array}$ & $\begin{array}{c}51.88 \\
(6.07) *\end{array}$ & $\begin{array}{c}2.22 \\
(0.72)\end{array}$ & $\begin{array}{c}3.72 \\
(0.13)\end{array}$ & $\begin{array}{c}42.99 \\
(14.06)\end{array}$ & $\begin{array}{l}72.02 \\
(2.49) *\end{array}$ \\
\hline PCL10 & $\begin{array}{c}47.29 \\
(0.96) *\end{array}$ & - & $\begin{array}{c}4.47 \\
(0.18)\end{array}$ & - & $\begin{array}{l}83.30 \\
(4.01) *\end{array}$ & - \\
\hline $6 \% \mathrm{Lu}, \mathrm{PCL} 40$ & $\begin{array}{l}90.98 \\
(1.06)\end{array}$ & - & $\begin{array}{c}4.74 \\
(0.20)\end{array}$ & - & $\begin{array}{l}96.80 \\
(1.62)\end{array}$ & - \\
\hline $13 \% \mathrm{Lu}, \mathrm{PCL} 40$ & $\begin{array}{l}90.57 \\
(3.79)\end{array}$ & - & 4.95 & - & 94.56 & - \\
\hline
\end{tabular}

Table 2: Released drug percentages for in vitro tested disks and disks implanted during 1 month or 2 months $(*, \mathrm{p} \leq 0.1$ statistically significant differences between in vitro and in vivo drug released percentages)

disks were fully encapsulated) and as such the released drug percentages are similar both in vitro and in vivo.

In Table 3, the non-linear regression results are presented. The objective behind fitting these equations to the release data was to understand the underlying phenomena involved in the drug release mechanism. Smaller values for $S_{0}$ suggest higher amounts of immobilized drug that will not be released (37.8\% for PCL40 and $16.6 \%$ for $13 \%$ Lu,PCL40). The percentage of immobilized drug is higher for PCL40 than for blend samples because in the latter case erosion creates more surface area and exposes more drug to water dissolution that otherwise would be trapped. In the case of the studied polymers, physical immobilization of the drug occurs due to drug entrapment in crystalline regions. Drug diffusion from these regions is hindered because water enters initially only in the amorphous parts. The immobilized fraction of the drug will be released only with polymer degradation (this explains why the steady state value of released drug percentage is smaller than 100 $\%$, which would correspond to total release).

The regression results obtained using power law equation reinforce the previous observations. The high value of $k$ indicates the extent of burst, higher for blend samples. The range of values for the release exponent is 


\begin{tabular}{|c|c|c|c|c|c|c|c|}
\hline \multirow[t]{2}{*}{ Sample } & \multicolumn{3}{|c|}{ Power law } & \multicolumn{4}{|c|}{ Degradation model } \\
\hline & $\begin{array}{c}k \\
\left(\text { day }^{-n}\right)\end{array}$ & $n$ & $\mathrm{R}_{a d j}^{2}$ & $A_{0}$ & $S_{0}$ & $\begin{array}{c}\mu \\
\left(\mathrm{day}^{-1}\right)\end{array}$ & $\mathrm{R}_{a d j}^{2}$ \\
\hline PCL40 & $\begin{array}{l}17.05 \\
(0.65)\end{array}$ & $\begin{array}{c}0.26 \\
(0.01)\end{array}$ & 0.98 & $\begin{array}{l}10.75 \\
(1.42)\end{array}$ & $\begin{array}{l}62.21 \\
(1.64)\end{array}$ & $\begin{array}{c}0.02 \\
(0.00)\end{array}$ & 0.96 \\
\hline PCL10 & $\begin{array}{l}24.11 \\
(0.60)\end{array}$ & $\begin{array}{c}0.19 \\
(0.01)\end{array}$ & 0.97 & $\begin{array}{c}15.86 \\
(1.67)\end{array}$ & $\begin{array}{l}51.45 \\
(1.86)\end{array}$ & $\begin{array}{c}0.04 \\
(0.00)\end{array}$ & 0.92 \\
\hline $6 \% \mathrm{Lu}, \mathrm{PCL} 40$ & $\begin{array}{l}41.31 \\
(3.14)\end{array}$ & $\begin{array}{c}0.27 \\
(0.03)\end{array}$ & 0.92 & $\begin{array}{c}5.90 \\
(1.33)\end{array}$ & $\begin{array}{l}84.12 \\
(1.46)\end{array}$ & $\begin{array}{c}0.42 \\
(0.03)\end{array}$ & 0.99 \\
\hline $13 \% \mathrm{Lu}, \mathrm{PCL} 40$ & $\begin{array}{r}56.23 \\
(3.53)\end{array}$ & $\begin{array}{c}0.17 \\
(0.02)\end{array}$ & 0.83 & $\begin{array}{c}7.01 \\
(0.66)\end{array}$ & $\begin{array}{l}83.41 \\
(0.69)\end{array}$ & $\begin{array}{c}1.66 \\
(0.04)\end{array}$ & 1.00 \\
\hline
\end{tabular}

Table 3: Model parameters determined by non-linear regression

indicative of a diffusion mechanism for drug release. This model fails to explain the last stage of the release (steady-state at less than $100 \%$ released drug) as it doesn't consider the effect of polymer degradation.

The release kinetics suggested a three stage release mechanism, with different steps depending on disk composition. Dissolution of the surface loaded drug and subsequent diffusion, followed by diffusion of the mobile drug through water-filled pores (created either due to Lu leaching or polymer recrystallization $[15,20]$ ), while the last stage was controlled by polymer degradation and subsequent diffusion of the immobilized drug. In blends, most of the drug is released due to polymer erosion, while the residual drug was released by diffusion through water-filled pores. The mechanism from PCL40/PCL10 disks and blend disks are essentially the same, except for the initial stage when drug diffusion is coupled with polymer erosion in the case of blends. By selecting the proper ratio between the components, the preponderance of a certain stage during drug release can be changed, obtaining an overall effect in drug release that fits the intended application.

\subsection{Intraocular pressure measurement}

In order to simulate ocular hypertension, we developed a rabbit glaucoma model by increasing the IOP values (Fig. 2(d)) from an average of $20.9 \mathrm{mmHg}$ (normotensive eyes) to an average of $30.1 \mathrm{mmHg}$ (hypertensive eyes). A second procedure was performed after 1 month because IOP values returned 


\begin{tabular}{lcccc}
\hline Sample & \multicolumn{3}{c}{ Average IOP reduction (\%) } \\
\cline { 2 - 3 } \cline { 4 - 5 } \cline { 4 - 5 } & Normotensive eyes & & Hypertensive eyes \\
\cline { 2 - 5 } & $16.55(10.94)$ & & $25.21(9.74)$ & $23.82(10.14)$ \\
Trusopt & $16.91(6.43)$ & & $41.06(12.16) *$ & $33.21(8.90)$ \\
PCL40 & $23.73(8.15)$ & & $39.61(11.90) *$ & - \\
PCL10 & $23.85(7.24)$ & & $39.24(15.21) *$ & - \\
6\%Lu,PCL40 & $16.59(8.02)$ & & - & - \\
13\%Lu,PCL40 & &
\end{tabular}

Table 4: Average IOP reduction $(*, \mathrm{p} \leq 0.01$ statistically significant differences between IOP percentages obtained by disk implantation relative to those obtained with Trusopt instillation)

to baseline after this period $[17,18]$. Disks were first tested in normotensive eyes in order to select the best performing systems. In Fig. 2(e) and Fig. 2(f), it can be seen that sample 13\%Lu,PCL40 decreased IOP by $16.6 \%$ (see also Table 4) reaching the baseline value after 15 days, while sample $6 \% \mathrm{Lu}, \mathrm{PCL} 40$ decreased IOP by $23.8 \%$ during 25 days. More sustained decrease in IOP was shown by sample PCL40 (16.9 \%) and PCL10 (23.7 \%) during the 30 days of test. The decrease in IOP obtained with the disks was comparable with the one obtained by applying Trusopt eyedrops ( $\mathrm{p} \geq 0.17$ for all disks). A decrease of at least $20 \%$ is desired in order to reduce the rate of open angle glaucoma-related damage [21].

Fig. 2(a) and Fig. 2(b) present IOP change in hypertensive eyes with implanted disks and in eyes treated with Trusopt ${ }^{\circledR}$ (Fig. 2(c)). PCL40 presented a decrease of $41.1 \%$ after 1 month and a decrease of $33.2 \%$ after 2 months, which is particularly suitable for patients with moderate to severe glaucoma [21]. IOP values in eyes with PCL40 implants are expected to approach the baseline values after approximately 3 months (see Fig. 1(b)). Samples PCL10 and 6\%Lu,PCL40 showed similar IOP decrease percentages and peak IOP percentage in hypertensive eyes, while peak IOP was attained faster for sample 6\%Lu,PCL40 due to faster drug release (see section 3.3). Thus, the release rate from the disks can be manipulated by blending in order to achieve the desired decrease in IOP.

Table 4 presents the average IOP decrease percentages achieved by the implanted disks in normotensive and hypertensive eyes, while Table 5 shows 


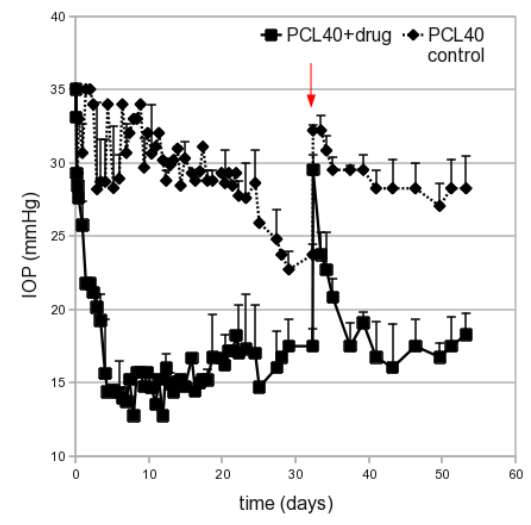

(a)

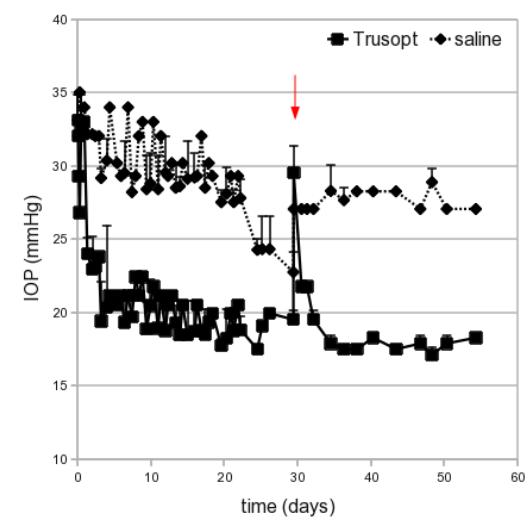

(c)

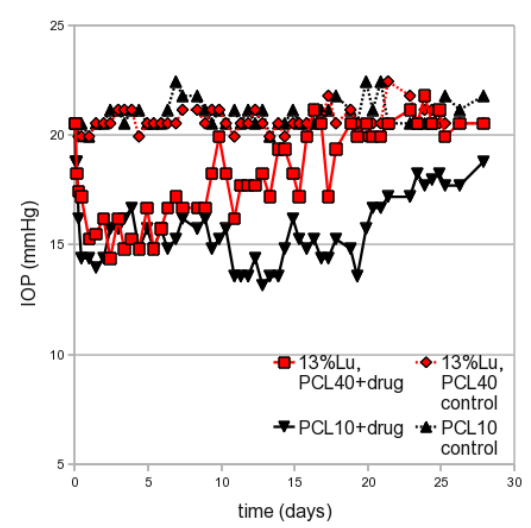

(e)

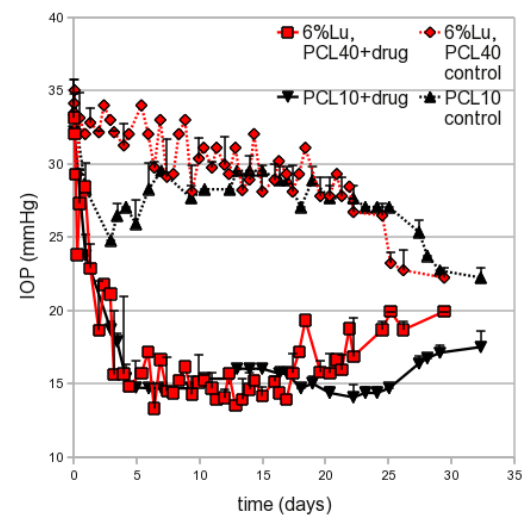

(b)

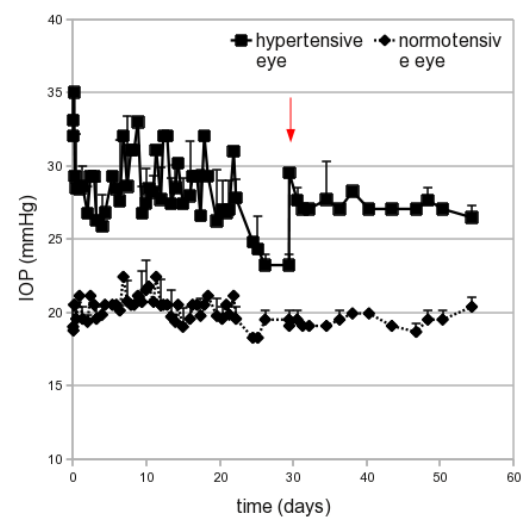

(d)

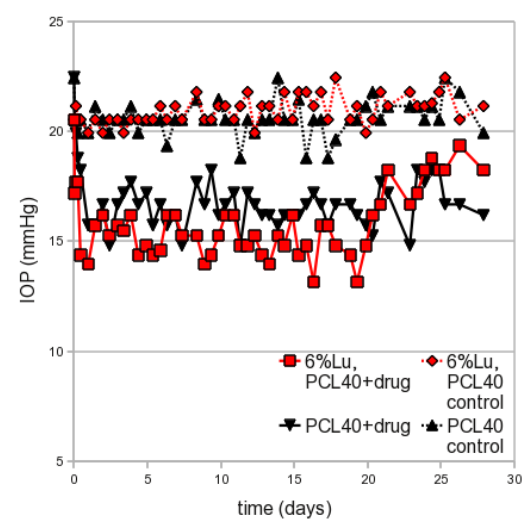

(f)

Figure 2: a), b) IOP in hypertensive eyes of group undergoing implant treatment, c) IOP in hypertensive eyes of group undergoing Trusqpf ${ }^{\circledR}$ eyedrops treatment, d) IOP in glaucoma model group, e), f) IOP in normotensive eyes of group undergoing implant treatment (the red arrow indicates the point when a second cauterization was performed) 


\begin{tabular}{|c|c|c|c|}
\hline \multirow[t]{3}{*}{ Sample } & \multicolumn{3}{|c|}{ Peak IOP reduction (\%)/time (days) } \\
\hline & \multirow{2}{*}{$\frac{\text { Normotensive eyes }}{1 \text { month }}$} & \multicolumn{2}{|c|}{ Hypertensive eyes } \\
\hline & & 1 month & 2 months \\
\hline Trusopt & $27.85 / 0.96$ & $36.59(2.37) / 3.38$ & $35.33(3.65) / 34.56$ \\
\hline PCL40 & $25.67 / 7.35$ & $55.26(0.98) / 6.90$ & $43.24(2.55) / 25.06$ \\
\hline PCL10 & $35.92 / 6.90$ & $50.21(0.00) / 6.94$ & - \\
\hline $6 \% \mathrm{Lu}, \mathrm{PCL} 40$ & $32.00 / 4.38$ & $55.23(5.03) / 3.18$ & - \\
\hline $13 \% \mathrm{Lu}, \mathrm{PCL} 40$ & $29.96 / 2.42$ & - & - \\
\hline
\end{tabular}

Table 5: Peak IOP and the time interval from instillation/implantation to peak IOP

the peak IOP decrease and the time interval from instillation/implantation to peak IOP. It can be noted that there was a higher IOP decrease in hypertensive eyes than in normotensive eyes for eyedrops and disks $(\mathrm{p} \leq 0.01$ for all disks). Sample PCL40 showed the best performance in vivo (constant decrease in IOP for longer time) due to more sustained drug release. The obtained values for IOP decrease with Trusopt ${ }^{\circledR}$ are in agreement with literature values for normotensive $([22,23])$ and hypertensive eyes $([24,25])$. There was a higher decrease in IOP for eyes treated with disks than in those treated with eyedrops ( $\mathrm{p} \leq 0.01$ for all disks) probably because of higher amounts of drug released by the disks (average in vitro release rate of $0.43(0.04) \mathrm{mg} /$ day for PCL40 or $1.34(0.12) \mathrm{mg} /$ day for PCL10 during 1 month versus 0.02 $\mathrm{mg} /$ day delivered by eyedrops ([19])). The changes in IOP obtained in the eyes with implanted disk are similar to those obtained with the Ocusert drug delivery system $([26])$. Trusopt ${ }^{\circledR}$ eyedrops produced the fastest decrease in IOP in normotensive eyes with peak IOP attained after 0.96 days, followed by blend disks in agreement with in vitro release results (peak IOP was reached fastest for blend disks with higher content of $\mathrm{Lu}$ ). In hypertensive eyes, the same trend in IOP decrease was maintained, but the average IOP and peak IOP values were higher than those obtained in normotensive eyes. Peak IOP occured at similar times in hypertensive eyes, except for Trusopt ${ }^{\circledR}$. Probably, dorzolamide administered by eyedrops might require multiple doses to build up to steady state levels of concentration in the cilliary processes that are required for IOP decrease in hypertensive eyes. 


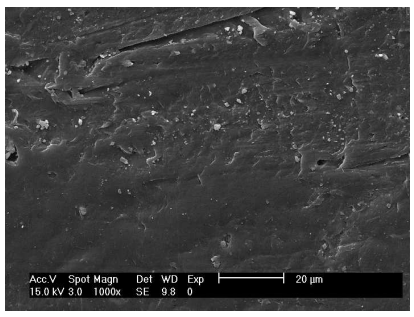

(a)

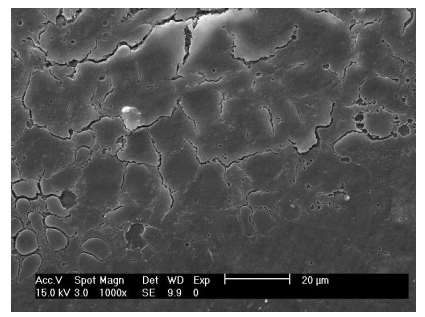

(d)

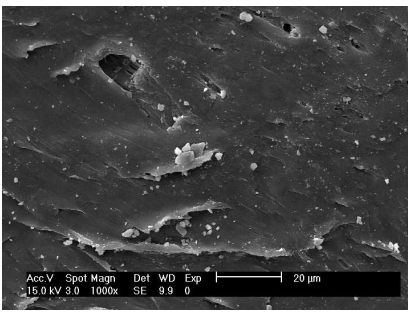

(b)

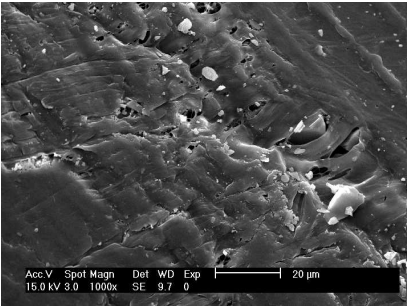

(e)

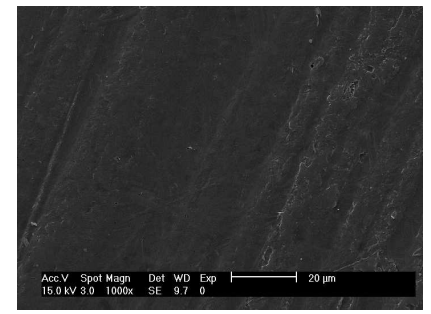

(c)

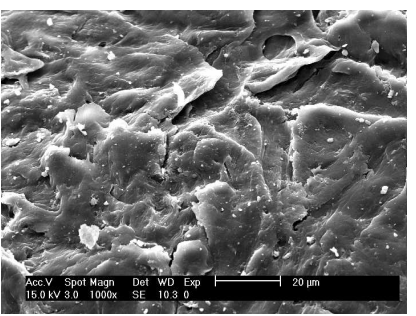

(f)

Figure 3: SEM of disks (with drug) surface. a) PCL40 as prepared, b) PCL40 in vivo, c) PCL10 as prepared, d) PCL10 in vivo, e) 6\%Lu,PCL40 as prepared, f) 6\%Lu,PCL40 in vivo

\subsection{Morphology and drug distribution, SEM and EPMA}

SEM and EMPA were performed in order to determine the morphology of the disks and the drug distribution inside the disks before and after the in vivo implantation.

Fig. 3(a) to Fig. 3(f) show the surface morphology of the prepared disks and in vivo degraded disks. There are significant signs of degradation on the implanted disk surface such as pores (Fig. 3(b)), cracks (Fig. 3(d)) and scales (Fig. 3(f)). The in vitro degraded samples showed fewer signs of material cracking (images not shown). This suggested enhanced degradation in vivo in comparison with in vitro conditions (see section 3.7).

After preparation, the disks presented a heterogeneous drug distribution (Fig. 4(a)) probably because of phase separation between drug and polymers due to the high drug loading. After in vivo testing, there was almost no drug at the surface (Fig. 4(b)), while in the disk cross-section there were still significant amounts of drug present in sample PCL40 after 1 month in vivo (Fig. 4(c)). The mapping of the other disks sections show that the release was complete after 1 month of implantation. 


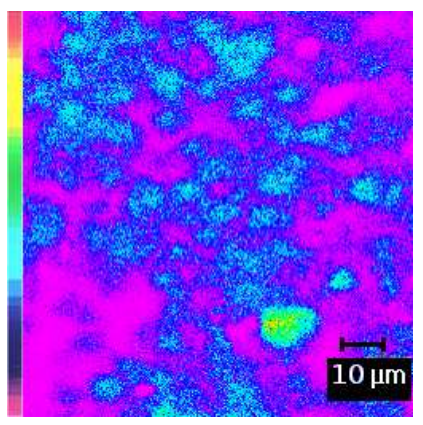

(a)

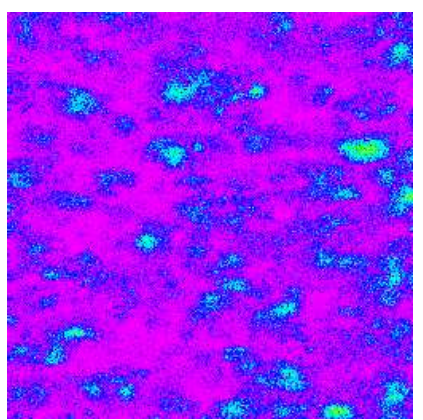

(d)

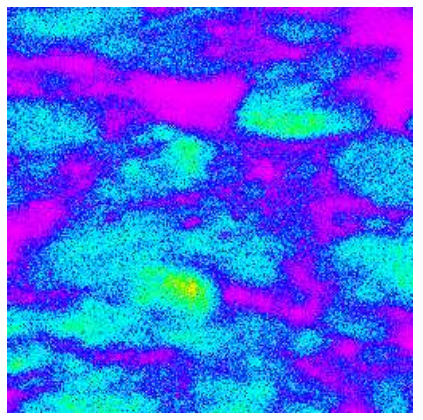

(g)

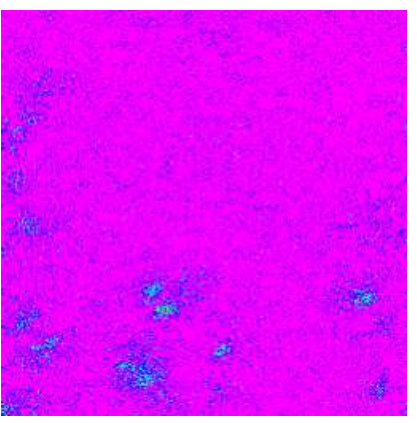

(b)

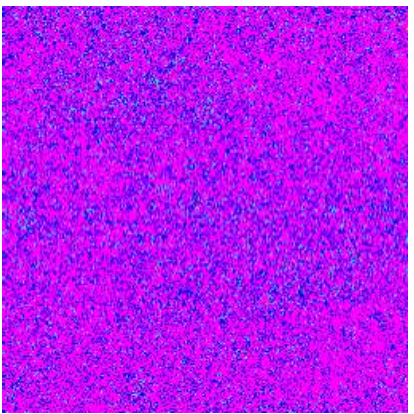

(e)

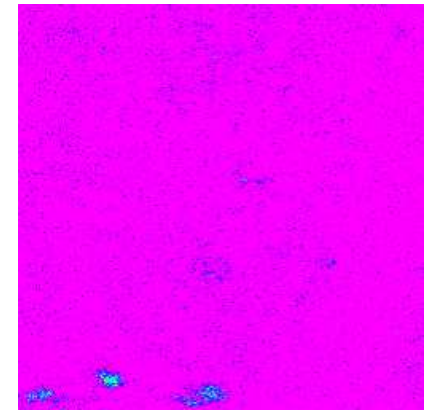

(h)

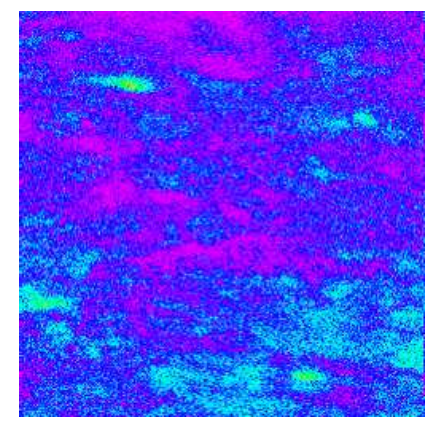

(c)

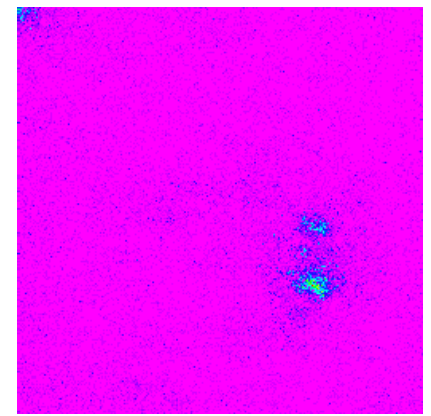

(f)

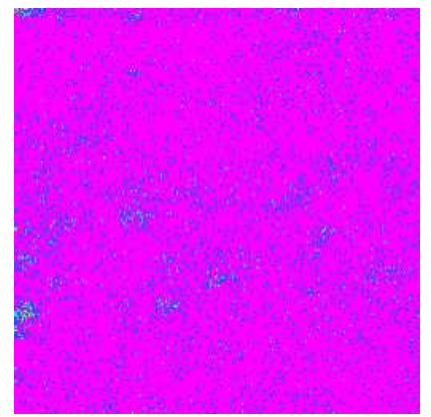

(i)

Figure 4: Sulphur drug mapping after 1 month in vivo. a) PCL40 surface as prepared, b) PCL40 surface in vivo, c) PCL40 section in vivo, d) PCL10 surface as prepared, e) PCL10 surface in vivo, f) PCL10 section in vivo, g) $6 \%$ Lu,PCL40 surface as prepared, h) $6 \% \mathrm{Lu}, \mathrm{PCL} 40$ surface in vivo, i) $6 \% \mathrm{Lu}, \mathrm{PCL} 40$ section in vivo (in the scale bar, the colour gradient represents 0\% drug (pink) and 100\% drug (red)) 


\subsection{In vitro and in vivo degradation}

To differentiate between a physical or a chemical degradation mechanism, the crystallinity and MW was determined for initial, in vitro and in vivo degraded samples (in section 6 , the table 6 presents the change of disk crystallinity and MW due to in vitro and in vivo degradation). There was MW decrease due to chemical hydrolysis for PCL40+drug sample both after 1 month and 2 months and for 6\%Lu,PCL40+drug after 1 month. Sample PCL10+drug did not degrade in vivo probably due to higher initial crystallinity as crystalline regions are more inaccessible to water uptake. The MW of the in vitro degraded samples was also determined, but the obtained differences were not statistically significant $(\mathrm{p} \geq 0.17)$. The samples presented lower crystallinity than the pure polymers (50.26 (0.33) \% for PCL40 and 68.51 (2.12) \% for Lu) and the drug loaded samples showed lower crystallinity than the control samples probably due to co-crystallization of dorzolamide (that is above the solubility limit in the polymer). In general, there was an increase in crystallinity for in vitro and in vivo degraded samples because the amorphous regions are degraded first and because during drug elution, the mobile polymer chains rearrange themselves and crystallize [15, 20]. Crystallinity was higher only for some in vivo degraded samples with respect to the in vitro degraded samples, suggesting that there is crystallinity increase and enhanced mechanical breakdown in vivo (see section 3.7).

\subsection{Histologic evaluation}

The tissue samples collected from various organs showed normal cell morphology. The histological analysis of the tissues from the implantation site showed rapid resolution of the acute and chronic inflammatory stages and the development of normal foreign body reaction, consisting of adherent macrophages (Fig. 5(b)), fibroblasts, lymphocytes and foreign body giant cells (Fig. 5(c)) on the surface of the disk and fibrous capsule formation (Fig. 5(d)). Blood vessels (Fig. 5(a)) that formed in the fibrous capsule were also observed. There was a higher density of cells on the drug loaded disk with respect to control disks. No acute and/or chronic inflammation was seen after 2 months, indicating that the disks were biocompatible and did not produce inflammatory reactions characteristic to toxic materials. 


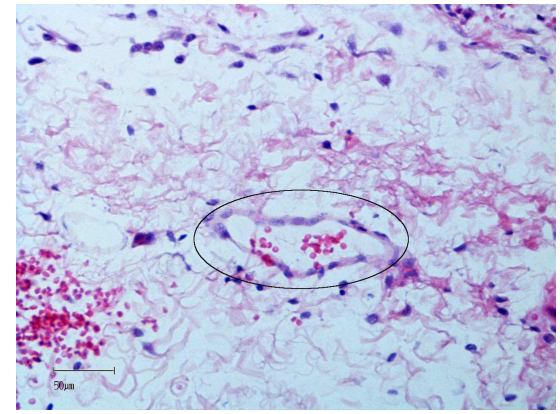

(a)

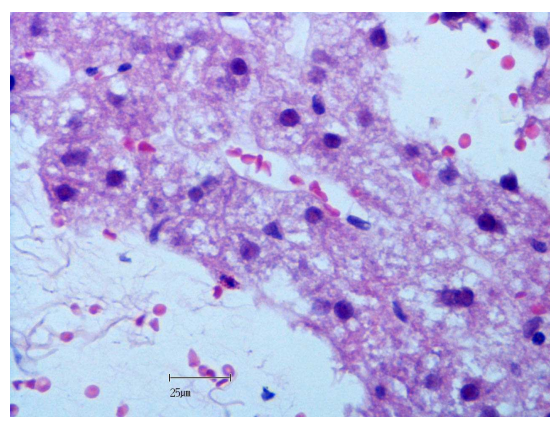

(c)

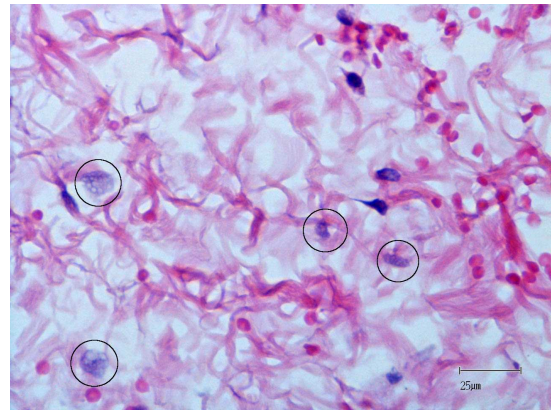

(b)

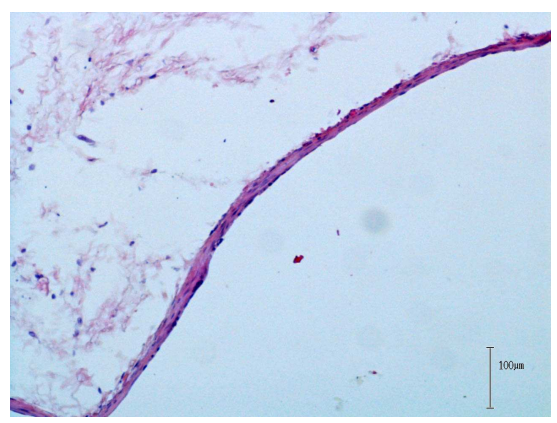

(d)

Figure 5: Light microscopy images of implanted disk showing a) cells and blood vessel (shown in the ellipse); b) macrophage cells (highlighted by circles); c) foreign-body giant cell; d) fibrous capsule

\section{Conclusions}

Subconjunctival disks based on PCL and loaded with dorzolamide hydrochloride were implanted in rabbit eyes and their in vivo performance was assessed by their capacity to lower IOP in normotensive and hypertensive eyes. The high MW PCL showed non-cumulative release rates above the therapeutic level during 3 months. Histologic analysis showed normal foreign body reaction response consisting of adherent macrophages, fibroblasts, lymphocytes, foreign body giant cells and fibrous capsule formation. The release kinetics suggested a three stage release mechanism based on drug diffusion, polymer erosion and polymer degradation, with different steps depending on disk composition. In vivo, the fibrous capsule formation around the PCL implant controls the drug release, working as a barrier membrane. For blend disks, due to polymer erosion that takes place mostly in the first 
day of release, the fibrous capsule/barrier control is absent.

In normotensive eyes, a $20 \%$ decrease in IOP obtained with the disks during 1 month was comparable with the one obtained by applying Trusopt ${ }^{\circledR}$ eyedrops. In hypertensive eyes, higher decrease percentages (around $40 \%$ ) were obtained for all samples, with the most sustained decrease from the high MW PCL (40\% after 1 month, $30 \%$ after 2 months). Peak IOP occured earlier for blend disks due to enhanced drug release triggered by polymer erosion. It was proven that the devices can lower IOP in sustained manner in a rabbit glaucoma model. The blending offers the possibility to manipulate release rate and the amount of released drug in order to prepare devices tailored to the needs of patients (target IOP decrease percentages should take into account risk factors and disease progression).

\section{Acknowledgements}

The authors would like to thank Merck Sharp \& Dohme Portugal for kindly supplying dorzolamide hydrochloride and Trusopt ${ }^{\circledR}$ eyedrops. FCT (Fundação para a Ciência e a Tecnologia) financial support is acknowledged by Mădălina V. Natu (SFRH/BD/30198/2006).

\section{References}

[1] H A Quigley (2005) Glaucoma: Macrocosm to Microcosm. Invest. Ophthalmol. Vis. Sci., doi:10.1167/iovs.041070

[2] K. Schwartz, D. Budenz (2004) Current management of glaucoma, Curr. Opin. Ophthalmol., 15, 119-126

[3] P.T. Khaw, P. Shah, A.R. Elkington (2004) Glaucoma-2: Treatment, Br. Med. J., doi:10.1136/bmj.328.7432.156

[4] E.M. del Amo, A. Urtti (2008) Current and future ophthalmic drug delivery systems A shift to the posterior segment, Drug Discov. Today, doi:10.1016/j.drudis.2007.11.002

[5] J.M. Korte, T. Kaila, K.M. Saari (2002) Systemic bioavailability and cardiopulmonary effects of $0.5 \%$ timolol eyedrops. Graefes Arch. Clin. Exp. Ophthalmol., doi:10.1007/s00417-002-0462-2 
[6] R.J. Noecker (2005) Evaluation of Bimatoprost 0.03\% versus Latanoprost 0.005\%: A Paired Comparison Study. Invest. Ophthalmol. Vis. Sci., 46, E-Abstract 2452.

[7] S.V. Kulkarni, K.F. Damji, Y.M. Buys (2008) Medical management of primary open-angle glaucoma: Best practices associated with enhanced patient compliance and persistency. Patient Prefer. Adherence, 2,303313

[8] B.K. Nanjawade, F.V. Manvi, A.S. Manjappa (2007) In situ-forming hydrogels for sustained ophthalmic drug delivery, J. Con. Rel., doi:10.1016/j.jconrel.2007.07.009

[9] J.L. Bourges, C. Bloquel, A. Thomas, F. Froussart, A. Bochot, F. Azan, R. Gurny, D. BenEzra, F. Behar-Cohen (2006) Intraocular implants for extended drug delivery: Therapeutic applications. Adv. Drug. Deliv. Rev., doi:10.1016/j.addr.2006.07.026

[10] M.V. Natu and M.N. Gaspar and C.A.F. Ribeiro and I.J. Correia and D. Silva and H.C. de Sousa and M.H. Gil (2011) A poly( $\varepsilon$-caprolactone) device for sustained release of an anti-glaucoma drug, Biomed. Mater., 6, 025003, doi: 10.1088/1748-6041/6/2/025003

[11] T. Yasukawa and Y. Ogura and E. Sakurai and Y. Tabata and H. Kimura (2005) Intraocular sustained drug delivery using implantable polymeric devices, Adv. Drug Deliv. Rev., 57, 2033-2046, doi: 10.1016/j.addr.2005.09.005

[12] N. Kuno and S. Fujii (2010) Biodegradable intraocular therapies for retinal disorders: progress to date, Drugs Aging, 27, 117-134, DOI:10.2165/11530970-000000000-00000

[13] J. Breitenbach (2002) Melt extrusion: from process to drug delivery technology, Eur. J. Pharm. Biopharm., 54, 107-117

[14] M.V. Natu, M.H. Gil, H.C. de Sousa (2008) Supercritical solvent impregnation of $\operatorname{poly}(\varepsilon$-caprolactone)/poly(oxyethylene-b-oxypropyleneb-oxyethylene) and poly(E-caprolactone)/poly(ethylene-vinyl acetate) blends for controlled release applications. J. Sup. Fluids, doi:10.1016/j.supflu.2008.05.006 
[15] M.V. Natu, H.C. de Sousa, M.H. Gil (2010) Effects of drug solubility, state and loading on controlled release in bicomponent electrospun fibers. Int. J. Pharm., doi:10.1016/j.ijpharm.2010.06.045

[16] C.G. Pitt, F.I. Chasalow, Y.M. Hibionada, D.M. Klimas, A. Schindler (1981) Aliphatic polyesters. I. The degradation of poly( $\varepsilon$-caprolactone) in vivo, J. Appl. Polym. Sci., doi:10.1002/app.1981.070261124

[17] H. Levkovitch-Verbin, H.A. Quigley, K.R.G. Martin, D. Valenta, L.A. Baumrind, M.E. Pease (2002) Translimbal Laser Photocoagulation to the Trabecular Meshwork as a Model of Glaucoma in Rats, Invest. Ophthalmol. Vis. Sci., 43, 402-410.

[18] J. Ruiz-Ederra, A.S. Verkman (2006) Mouse model of sustained elevation in intraocular pressure produced by episcleral vein occlusion. Exp. Eye Res., doi:10.1016/j.exer.2005.10.019

[19] K. Schmitz, P. Banditt, M. Motschmann, F. P. Meyer, W. BehrensBaumann (1999) Population Pharmacokinetics of 2\% Topical Dorzolamide in the Aqueous Humor of Humans, Invest. Ophthalmol. Vis. Sci., 40, 1621-1624.

[20] M. Miyajima, A. Koshika, J. Okada, M. Ikeda, K. Nishimura (1997) Effect of polymer crystallinity on papaverine release from poly(L-lactic acid) matrix. J. Con. Rel., doi:10.1016/S0168-3659(97)00081-3

[21] L. Yudcovitch, Pharmaceutical, Laser and Surgical Treatments for Glaucoma: An Update, http://www.pacificu.edu/optometry/ce/ courses/15166/pharglapg2.cfm\#Pharmaceutical, Accessed October $15,2010$.

[22] A. Harris, O. Arend, H.S. Chung, L. Kagemann, L. Cantor, B. Martin (2000) A comparative study of betaxolol and dorzolamide effect on ocular circulation in normal-tension glaucoma patients. Ophthalmol., 107, 430-434

[23] A. Scozzafava, L. Menabuoni, F. Mincione, F. Briganti, G. Mincione, C.T. Supuran (1999) Carbonic Anhydrase Inhibitors. Synthesis of 
Water-Soluble, Topically Effective, Intraocular Pressure-Lowering Aromatic/Heterocyclic Sulfonamides Containing Cationic or Anionic Moieties: Is the Tail More Important than the Ring? J. Med. Chem., doi:10.1021/jm9900523

[24] A.G. Konstas, V.P. Kozobolis, S. Tsironi, I. Makridaki, R. Efremova, W.C. Stewart (2008) Comparison of the 24-hour intraocular pressure-lowering effects of latanoprost and dorzolamide/timolol fixed combination after 2 and 6 months of treatment. Ophthalmol., doi:10.1016/j.ophtha.2007.03.007

[25] M. Seki, T. Tanaka, H. Matsuda, T. Togano, K. Hashimoto, J. Ueda, T. Fukuchi, H. Abe (2005) Topically administered timolol and dorzolamide reduce intraocular pressure and protect retinal ganglion cells in a rat experimental glaucoma model. Br. J. Ophthalmol., doi:10.1136/bjo.2004.052860

[26] K.L. Macoul, D. Pavan-Langston (1975) Pilocarpine Ocusert System for Sustained Control of Ocular Hypertension. Arch. Ophthalmol., 93, $587-590$

\section{Supplementary information}




\begin{tabular}{|c|c|c|c|c|c|c|c|c|c|}
\hline \multirow[t]{3}{*}{ Sample } & \multirow{3}{*}{$\begin{array}{c}\text { As } \\
\text { prepared }\end{array}$} & \multicolumn{2}{|c|}{ In vitro } & \multicolumn{6}{|c|}{ In vivo } \\
\hline & & $\mathrm{X}_{r e l}$ & mass & $\mathrm{X}_{r e l}$ & mass & $M_{w}(\mathrm{~g}$ & (mole) & $\Delta \Lambda$ & $(\%)$ \\
\hline & & \multicolumn{2}{|c|}{1 month } & \multicolumn{2}{|c|}{1 month } & $\begin{array}{c}1 \\
\text { month }\end{array}$ & $\begin{array}{c}2 \\
\text { months }\end{array}$ & $\begin{array}{c}1 \\
\text { month }\end{array}$ & $\begin{array}{c}2 \\
\text { months }\end{array}$ \\
\hline PCL40+drug & $\begin{array}{l}36.97 \\
(1.93)\end{array}$ & $\begin{array}{l}29.13 \\
(0.97)\end{array}$ & $\begin{array}{l}13.46 \\
(1.14)\end{array}$ & $\begin{array}{c}38.89 \\
(0.03) \dagger\end{array}$ & $\begin{array}{l}15.07 \\
(4.93)\end{array}$ & $\begin{array}{c}62377.5 \\
(725.5)\end{array}$ & $\begin{array}{c}60274.5 \\
(112.4)\end{array}$ & $4.9 *$ & $8.1 *$ \\
\hline PCL40 & $\begin{array}{l}50.26 \\
(0.33)\end{array}$ & $\begin{array}{l}43.62 \\
(1.27)\end{array}$ & $\begin{array}{c}0.74 \\
(0.11)\end{array}$ & $\begin{array}{l}46.13 \\
(1.62)\end{array}$ & $\begin{array}{c}0.90 \\
(0.07)\end{array}$ & $\begin{array}{l}62727.3 \\
(3555.6)\end{array}$ & $\begin{array}{l}57653.5 \\
(210.0)\end{array}$ & 4.4 & $12.1 *$ \\
\hline PCL10+drug & $\begin{array}{l}40.06 \\
(0.15)\end{array}$ & $\begin{array}{l}42.26 \\
(4.36)\end{array}$ & $\begin{array}{l}22.68 \\
(1.76)\end{array}$ & $\begin{array}{l}50.66 \\
(1.48)\end{array}$ & $\begin{array}{l}30.75 \\
(1.19)\end{array}$ & $\begin{array}{l}16906.5 \\
(2556.2)\end{array}$ & - & 10.8 & \\
\hline PCL10 & $\begin{array}{l}56.41 \\
(0.34)\end{array}$ & - & $\begin{array}{l}1.73 \\
(0.42)\end{array}$ & $\begin{array}{l}60.85 \\
(1.51)\end{array}$ & $\begin{array}{c}2.98 \\
(0.21)\end{array}$ & $\begin{array}{c}15152.5 \\
(55.9)\end{array}$ & - & 0.7 & - \\
\hline $6 \% \mathrm{Lu}, \mathrm{PCL} 40+\mathrm{drug}$ & $\begin{array}{l}32.12 \\
(0.17)\end{array}$ & $\begin{array}{l}38.51 \\
(0.72)\end{array}$ & $\begin{array}{l}36.77 \\
(0.01)\end{array}$ & $\begin{array}{c}47.18 \\
(0.70) \dagger\end{array}$ & $\begin{array}{l}33.37 \\
(0.48)\end{array}$ & $\begin{array}{c}60625.5 \\
(102.5)\end{array}$ & - & $7.6 *$ & - \\
\hline $6 \% \mathrm{Lu}, \mathrm{PCL} 40$ & $\begin{array}{l}43.41 \\
(0.19)\end{array}$ & - & $\begin{array}{l}1.30 \\
(0.10)\end{array}$ & $\begin{array}{l}45.15 \\
(1.79)\end{array}$ & $\begin{array}{l}1.51 \\
(0.14)\end{array}$ & $\begin{array}{l}58144.5 \\
(748.8)\end{array}$ & - & $11.4 *$ & - \\
\hline $13 \% \mathrm{Lu}, \mathrm{PCL} 40+$ drug & $\begin{array}{l}30.32 \\
(0.52)\end{array}$ & $\begin{array}{l}41.43 \\
(0.56)\end{array}$ & $\begin{array}{l}41.12 \\
(0.45)\end{array}$ & $\begin{array}{l}44.07 \\
(2.69)\end{array}$ & 37.36 & $\begin{array}{l}61636.5 \\
(2686.3)\end{array}$ & - & 6.0 & - \\
\hline 13\%Lu,PCL40 & $\begin{array}{l}38.40 \\
(1.13)\end{array}$ & - & $\begin{array}{l}7.71 \\
(0.56)\end{array}$ & $\begin{array}{l}44.43 \\
(2.96)\end{array}$ & 5.84 & 61606 & - & 6.1 & - \\
\hline
\end{tabular}

Table 6: Crystallinity, mass loss and molecular weight evolution for in vitro and in vivo degraded samples $(\mathrm{p} \leq 0.05, *$, relative to initial MW, $\dagger$, relative to in vitro crystallinity) 